\title{
Efeito da Velocidade de Soldagem nas Características Geométricas e Microestruturais de Soldas por Arco Submerso em Tandem Arc
}

Túlio Albuquerque Farias ${ }^{1}$, Ana Carla Santos da Silva ${ }^{1}$ (D) , Erike Wilker Arruda Figueredo ${ }^{1}$ (D), Marcos Pereira ${ }^{1}$, Flávio José da Silva ${ }^{1}$

${ }^{1}$ Universidade Federal de Pernambuco, Departamento de Engenharia Mecânica, Recife, PE, Brasil.

Como citar: Farias TA, Silva ACS, Figueredo EWA, Pereira M, Silva FJ. Influence of Welding Speed on Geometric and Microstructural Characteristics of Submerged Arc Welding Tandem Arc Joints. Soldagem \& Inspeção. 2021;26:e2609. https://doi.org/10.1590/0104$9224 / \mathrm{S} 126.09$

\begin{abstract}
Resumo: A soldagem a arco submerso tem recebido atenção crescente na indústria devido a sua propensão a altas produtividades, que podem atingir níveis ainda maiores através da variante tandem arc (SAW-T). Este trabalho avalia a influência da velocidade de soldagem nas características geométricas e microestruturais de juntas soldadas por SAW-T com dois arames, em dois passes opostos. Para isso, fabricou-se, em velocidades de soldagem distintas, três juntas a partir de chapas de aço estrutural, em dois passes opostos cada. Avaliou-se a geometria dos cordões, a microestrutura e a distribuição de dureza ao longo da seção transversal das juntas. Aumentos de velocidade de soldagem mostraramse detrimentais à geometria dos cordões. As zonas fundidas formadas consistem majoritariamente em variadas morfologias de ferrita, com maiores teores de ferrita acicular em amostras de velocidades de soldagem mais altas. Foram identificadas ilhas de bainita no interior de grãos nas zonas termicamente afetadas, além de outros tipos de ferrita. Os valores de dureza sofreram suave aumento com acréscimos de velocidade e não indicam suscetibilidade a trincas. As velocidades mais altas resultaram em juntas com falta de penetração, defeito que indica aporte térmico insuficiente. A junta soldada a $1200 \mathrm{~mm} / \mathrm{min}$ apresentou boa geometria e microestrutura refinada.
\end{abstract}

Palavras-chave: Soldagem a Arco Submerso; Tandem Arc; Análise Microestrutural; Caracterização de Materiais; Parâmetros de Soldagem.

\section{Influence of Welding Speed on Geometric and Microstructural Characteristics of Submerged Arc Welding Tandem Arc Joints}

\begin{abstract}
Industry interest in submerged arc welding processes has been growing due to its high productivity rates, which can be further increased through tandem arc techniques. This study evaluates the effect of welding speed on geometric and microstructural characteristics of weldments produced by two wires SAW-T, with two opposite beads each. For this purpose, three structural steel welding joints were manufactured, each using a different welding speed. The weldments' microstructure, bead geometry and hardness distribution were analyzed. Bead geometry suffered negative effect from higher speeds. The welded zones formed consisted mainly of assorted ferrite morphologies, with more acicular ferrite in joints welded under higher welding speeds. Bainite islands were present intragranularly in the heat affected zones, among ferrite microconstituents. Hardness values were slightly raised under higher welding speeds and do not suggest crack susceptibility. None of the weldments produced contained any martensite microconstituents. The highest welding speeds resulted in lack of fusion defects in the weldments, suggesting insufficient heat input and penetration. The joint welded using $1200 \mathrm{~mm} / \mathrm{min}$ speed showed good geometry and refined microstructure, indicating that this condition is promising as a way to manufacture sturdy steel weldments under high productivity rates.
\end{abstract}

Keywords: Submerged Arc Welding; Tandem Arc; Microstructural Analysis; Materials Characterization; Welding Parameters.

\section{Introdução}

A soldagem é um processo empregado rotineiramente pelas indústrias naval, petroquímica e da construção civil para unir peças metálicas e obter produtos como oleodutos, vasos de pressão, embarcações e pontes [1,2]. A busca constante por maior participação no mercado tem induzido, nesses setores, o interesse por técnicas de soldagem cada vez mais automatizadas, produtivas e de menor custo. Essa tendência, somada ao fato de que essas soldas tendem a apresentar grandes espessuras e longos cordões, justifica a aplicação da soldagem a Arco Submerso (SAW), processo com altas taxas de deposição e produtividade e de fácil automatização [3,4]. 
A SAW é um processo de união de materiais metálicos por fusão em que calor é fornecido através de arco elétrico gerado entre um arame sólido e a peça de trabalho. O arame é continuamente alimentado e atua simultaneamente como eletrodo e metal de adição. O arco é envolvido por camadas de material granular, o fluxo, que é levado à junta por ação gravitacional, fornecendo elementos de liga para ajuste de composição do material fundido e proteção contra oxidantes atmosféricos, além de promover a formação de escória sobre o cordão soldado, protegendo o mesmo durante a solidificação e o resfriamento. Como a camada de fluxo formada em torno do arco durante o processo restringe respingos, emissão de radiação nociva e fumos de soldagem, os riscos ocupacionais comparativamente menores que em outros processos a arco elétrico. Processos SAW apresentam, ainda, possibilidade de execução a velocidades de soldagem consideráveis e com boa penetração [1,5,6].

Devido à competitividade presente no mercado dos setores em que o SAW é difundido, tem-se estudado e desenvolvido técnicas que permitam alcançar produtividades ainda maiores [3,6]. A soldagem a arco submerso tandem arc (SAW-T) é uma variante do SAW em que se utiliza dois ou mais arames, alinhados na direção de soldagem, a fim de aumentar as taxas de deposição e viabilizar maiores velocidades de soldagem para juntas de uma mesma espessura. Em processos tandem arc, cada arame é conectado a uma fonte de energia individual, com controle próprio dos parâmetros de soldagem, de modo que o aporte térmico é fornecido à junta através de múltiplos arcos elétricos. 0 emprego dessa variante de processo viabiliza a redução do número de passes necessários para a soldagem de chapas mais espessas, reduzindo o tempo dispendido durante a soldagem e eliminando a etapa de limpeza entre passes sobrepostos subsequentes [3,5,7].

Para que se possa trabalhar com maiores taxas de deposição sem comprometer a qualidade da junta soldada, é indispensável a parametrização adequada do processo de soldagem tandem arc. Os parâmetros de controle mais importantes no SAW, por exercerem a maior influência nas taxas de deposição, geometria do cordão e propriedades mecânicas da junta, são a corrente de soldagem ${ }_{L}$ definida por intensidade e polaridade, tensão de soldagem, velocidade de avanço do arame e velocidade de soldagem. A implementação da variante SAW-T é associada à manipulação de importantes parâmetros adicionais, como a distância e a inclinação entre os arames [6,8,9].

Aumentos de velocidade de soldagem tem impacto negativo nos principais parâmetros geométricos do cordão, visto que a redução de aporte térmico provocada reduz a quantidade de metal fundido e depositado $[1,9,10]$. A profundidade de penetração, em especial, tem comportamento limitante em relação à velocidade de soldagem, uma vez que com a deslocamento mais rápido do arco a camada de metal fundido se estreita, resultando em menor condução de corrente e de calor na junta [5,10]. Portanto, para que a aplicação de maiores velocidades de soldagem seja bem-sucedida, a fim de assegurar calor suficiente para penetração satisfatória, é preciso que os valores de corrente e tensão de soldagem sejam definidos de forma a compensar o menor tempo de interação entre o arco e a junta [1,9].

Dessa forma, há um limite até o qual se pode incrementar a velocidade de soldagem sem tornar insuficiente a penetração. O uso de arames múltiplos, como no caso do SAW-T, eleva esse limite de velocidade de soldagem. A redução de aporte térmico provocada pelos acréscimos de velocidade pode também provocar reduções no tamanho da zona termicamente afetada (ZTA) e das tensões residuais. O resfriamento mais rápido e a permanência mais breve a altas temperaturas, que limita o crescimento de grão austenítico, favorecem a ocorrência de ferrita acicular e o refinamento da mesma. Esse microconstituinte parte de nucleação intragranular e apresenta crescimento adifusional radial em várias direções, o que leva a formação caótica de ripas cristalograficamente desorientadas entre si, com comprimento aproximado entre 5 e $15 \mu \mathrm{m}$ e de 1 a $3 \mu \mathrm{m}$ de espessura [9,11-15]. A ausência de paralelismo entre as interfaces faz com que a configuração seja mais resistente à propagação de trincas, o que eleva a tenacidade do aço. Taxas de resfriamento mais altas elevam o superresfriamento, que atua como força motriz da nucleação. Com maiores taxas de nucleação, tem-se menos espaço disponível ao crescimento das agulhas, o que resulta em arranjo fino de grãos intertravados [14,15].

Considerado o contexto apresentado, o presente trabalho teve por objetivo avaliar as características de juntas de aço ASTM A572 Gr. 50. soldadas por arco submerso tandem arc com altas velocidades de soldagem, com uso de chanfro reto e reduzido número de passes de. Além disso, analisou-se o efeito de incrementos de velocidade sobre a microestrutura e geometria dos cordões. Para tanto, foram analisadas a profundidade de penetração, a altura de reforço, a largura do cordão e as características microestruturais das juntas produzidas em três condições de soldagem, dentre as quais variou-se somente a velocidade de soldagem, mantendo fixos os demais parâmetros do processo. Os resultados permitiram atingir melhor compreensão da influência desse parâmetro nos cordões soldados, e podem auxiliar a fundamentação de aumentos de produtividade de processos SAW-T em aplicações industriais, em especial no uso dos parâmetros estudados na Patente PI0802712-9 A2 [1].

\section{Materiais e Procedimento Experimental}

Os corpos de prova foram confeccionados a partir de chapas de $16 \mathrm{~mm}$ de espessura do aço ASTM A572 GR. 50, tendo como material de adição o arame de soldagem de especificação AWS 5.17: F6A4-EL12, de 4 mm de diâmetro, para todos os passes realizados. A Tabela 1 indica as propriedades mecânicas do metal de base segundo certificado fornecido pelo fabricante, além da composição química determinada por análise de espectrometria de emissão óptica. O fluxo aglomerado utilizado, de nome comercial OK FLUX 10.71, é caracterizado como básico, e com índice de basicidade igual a 1,6 conforme certificado 
disponibilizado pelo fabricante. As características do fluxo encontram-se dispostas na Tabela 2. Como metal de adição do processo, utilizou-se o arame AWS A5.17: F6A4-EL12, cujas características encontram-se dispostas na Tabela 3.

Tabela 1. Composição química e propriedades mecânicas do metal de base.

\begin{tabular}{|c|c|c|c|c|c|c|c|c|c|c|c|c|}
\hline \multicolumn{9}{|c|}{ Composição química* (\%) } & \multicolumn{3}{|c|}{ Propriedades mecânicas } & \multirow{2}{*}{$\begin{array}{l}\text { Carbono equiva- } \\
\text { lente }(\%)^{3}\end{array}$} \\
\hline C & Mn & $\mathbf{P}$ & $\mathbf{S}$ & Si & $\mathrm{Cr}$ & $\mathrm{Ni}$ & $\mathrm{Cu}$ & Al & $\mathrm{LE}^{1}$ (MPa) & $\begin{array}{c}\mathrm{LR}^{2} \\
(\mathrm{MPa})\end{array}$ & LE/LR & \\
\hline 0,15 & 0,68 & 0,04 & 0,01 & 0,19 & 0,06 & 0,02 & 0,07 & 0,03 & 345 & 450 & 0,77 & 0,281 \\
\hline
\end{tabular}

Fonte: Simisa, 2020

Tabela 2. Composição química e propriedades mecânicas do fluxo.

\begin{tabular}{|c|c|c|c|c|c|c|c|c|c|c|}
\hline \multicolumn{7}{|c|}{ Composição química (\%) } & \multicolumn{3}{|c|}{ Propriedades Mecânicas } & \multirow{2}{*}{$\begin{array}{c}\text { Carbono Equivalente } \\
(\%)^{3}\end{array}$} \\
\hline C & $M n$ & $\mathbf{P}$ & $S$ & $\mathbf{S i}$ & $\mathrm{Cu}$ & Al & $\mathrm{LE}^{1}$ (MPa) & $\mathrm{LR}^{2}(\mathrm{MPa})$ & LE/LR & \\
\hline 0,04 & 1,54 & 0,02 & 0,02 & 0,42 & 0,06 & 0,01 & 410 & 500 & 0,82 & 0,304 \\
\hline
\end{tabular}

Fonte: Esab, 2019.

Tabela 3. Composição química e propriedades mecânicas do metal de adição.

\begin{tabular}{|c|c|c|c|c|c|c|}
\hline \multicolumn{3}{|c|}{ Composição química (\%) } & \multicolumn{3}{|c|}{ Propriedades Mecânicas } & \multirow{2}{*}{$\begin{array}{l}\text { Carbono Equivalente } \\
\qquad(\%)^{3}\end{array}$} \\
\hline C & Mn & Si & $\mathrm{LE}^{1}(\mathrm{MPa})$ & $\mathrm{LR}^{2}(\mathrm{MPa})$ & LE/LR & \\
\hline 0,09 & 0,50 & $<0,10$ & 360 & 465 & 0,77 & 0,30 \\
\hline
\end{tabular}

Fonte: Esab, 2019. ${ }^{1}$ - Limite de escoamento; ${ }^{2}$ - Limite de resistência à tração; ${ }^{3}$ - Carbono equivalente segundo o International Institute of Welding.

Todo o procedimento de fabricação dos corpos de prova ocorreu no Centro de Aplicação ESAB em Contagem - MG. A soldagem foi realizada com dois conjuntos compostos por uma fonte inversora Aristo AC/DC 1000, uma tocha e um sistema de alimentação de fluxo para cada tocha de soldagem. Cada conjunto esteve associado a um dos arames, formando uma única torre de soldagem. A configuração utilizada está representada na Figura 1.

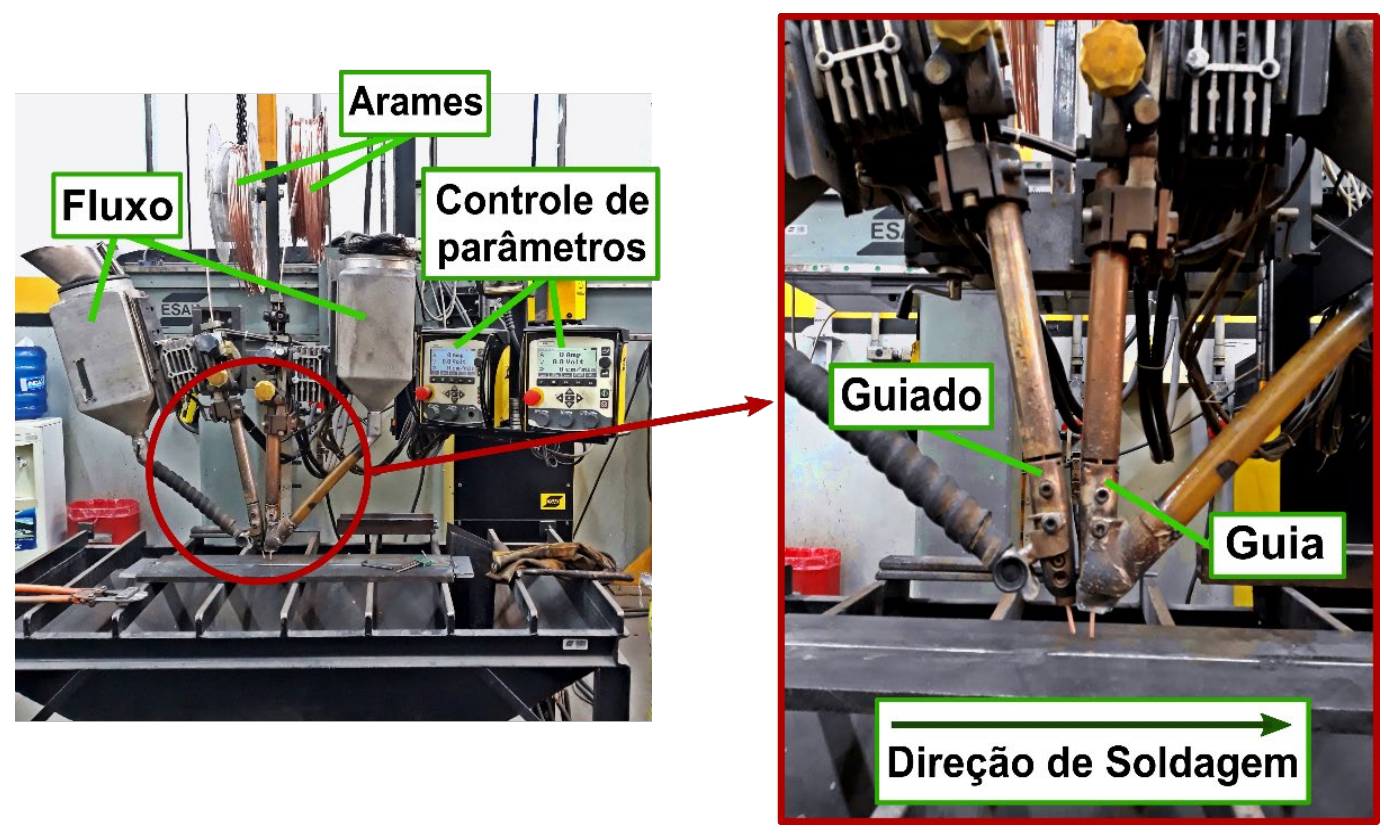

Figura 1. Montagem dos equipamentos de soldagem utilizados - à exceção das fontes inversoras.

A tocha de soldagem montada mais à frente na direção de soldagem - guia - foi configurada em orientação vertical e corrente contínua (DC), com eletrodo ligado ao terminal positivo. A tocha seguinte - guiada - teve sua orientação fixada a 15o em relação à tocha guia e configurada para corrente alternada ( $A C)$. A distância do arame à peça (stick-out) foi ajustada para 
$25 \mathrm{~mm}$ para o arame guia e $30 \mathrm{~mm}$ para o arame guiado, com $25 \mathrm{~mm}$ de distância entre os arames. 0 arranjo espacial descrito é ilustrado pela Figura 2 .

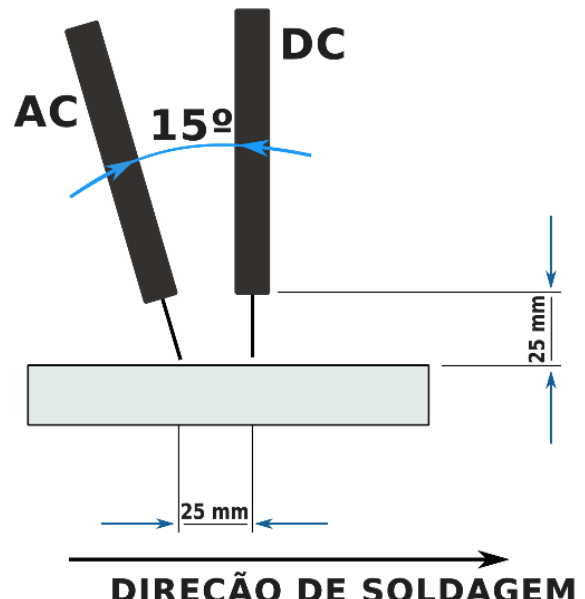

Figura 2. Configuração espacial dos arames no processo de soldagem.

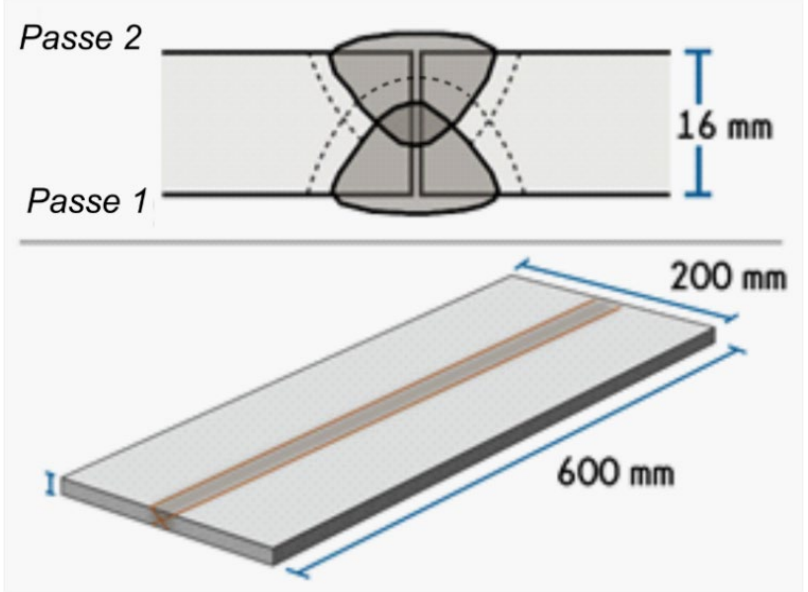

Figura 3. Representação gráfica das juntas confeccionadas.

Dessa forma, foram soldadas juntas de topo na posição plana (1G), com chanfro reto e sem abertura de raiz. Não foram realizados tratamentos térmicos pós-soldagem e o processo se deu de forma que o primeiro passe não proporcionou préaquecimento ao segundo, devido ao intervalo de tempo entre a realização de cada um deles. As juntas projetadas são representadas esquematicamente pela Figura 3.

Em relação aos aportes térmicos semelhantes ou mesmo inferiores, o uso da configuração tandem arc tem sido associado a velocidades consideravelmente superiores às empregadas em processos SAW convencional que apresentam em média valores próximos a $800 \mathrm{~mm} / \mathrm{min}$ [1]. Dessa forma, a parametrização do processo SAW-T foi realizada para velocidades de soldagem de 1200 a 1600 mm/min. A Tabela 4 exibe a lista de parâmetros selecionados para confecção das juntas.

Tabela 4. Parâmetros selecionados para os processos de soldagem.

\begin{tabular}{rccccc}
\hline Amostra & $\begin{array}{c}\text { Velocidade } \\
(\mathbf{m m} / \mathbf{m i n})\end{array}$ & Arame & Corrente (A) & Tensão (V) & Aporte Térmico (kJ/mm) \\
\multirow{2}{*}{ T120 } & 1200 & Guia & $950 \mathrm{DC}+$ & 33 & 2,80 \\
& \multirow{2}{*}{1400} & Guiado & $650 \mathrm{AC}$ & 38 & 2,40 \\
T140 & Guia & $950 \mathrm{DC}+$ & 38 & 33 \\
& \multirow{2}{*}{ T160 } & Guiado & $650 \mathrm{AC}$ & 33 & 2,10 \\
\hline
\end{tabular}


Conforme esquematizado na Figura 4, corpos de prova para análises macrográficas e de microscopia óptica e eletrônica de varredura foram retirados das juntas soldadas. Descartou-se o material correspondente às extremidades dos cordões, de forma que o estudo incluísse apenas a porção do cordão soldada sob arco elétrico estável.

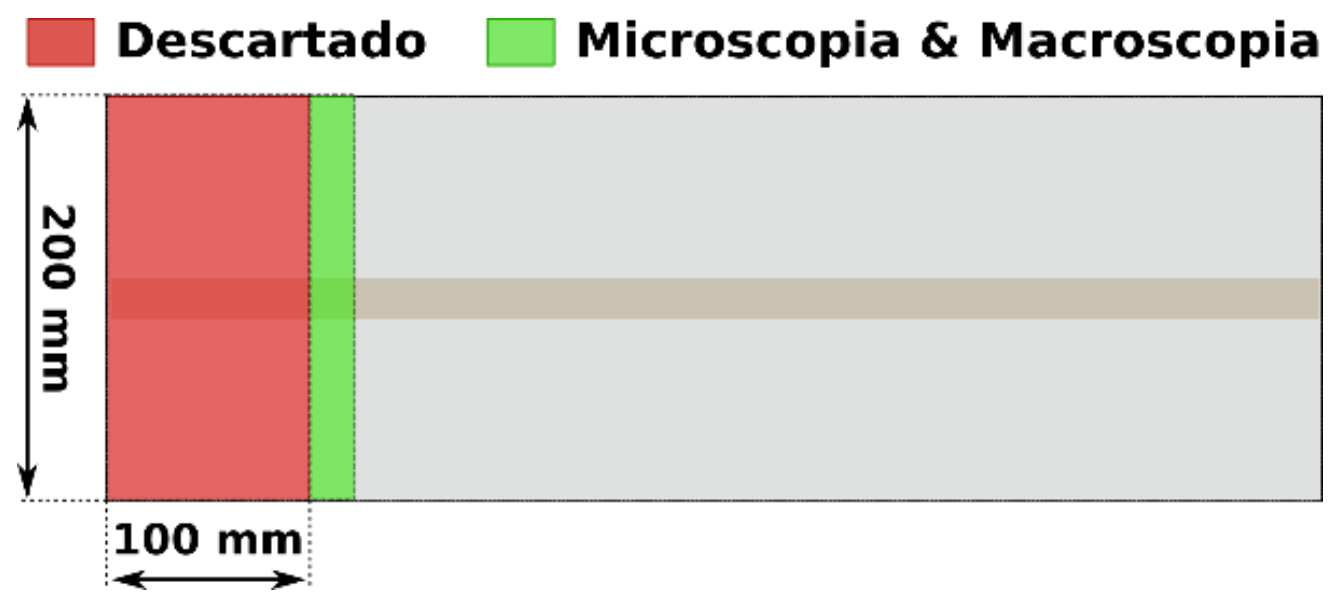

Figura 4. Ilustração esquemática do procedimento de retirada de amostras, vista de topo.

Uma vez retiradas e seccionadas por processo de corte refrigerado, as amostras tiveram a superfície transversal ao cordão de solda preparadas com lixas d'água de granulometrias de \#100, \#180, \#220, \#320, \#400, \#600, \#1200, listadas em ordem de utilização. Em seguida, foi realizado polimento das superfícies com pastas abrasivas de diamante em duas granulometrias, sendo a inicial de $3 \mu \mathrm{m}$ e a final de $1 \mu \mathrm{m}$. Por fim, as superfícies foram submetidas à ataque químico por imersão em Nital $5 \%$ por 10 segundos para propiciar a visualização dos contornos de grão e o contraste entre microestruturas. Ao final da imersão, as amostras foram lavadas em água destilada e álcool etílico e secadas com auxílio de soprador térmico.

Para análise macrográfica do perfil dos cordões de solda foi empregado um estereoscópio da marca Zeiss com aumento fixado em 10 vezes. As imagens obtidas nessa etapa foram analisadas no software de livre acesso ImageJ ${ }^{\circledR}$ para medições de parâmetros geométricos e cálculo de diluição, definida como a razão entre a área fundida do metal de base e a área fundida total. As imagens de microscopia foram obtidas com auxílio de microscópio óptico da marca Axion com aumentos de 100 a 500 vezes, e microscópio eletrônico de varredura com espectroscopia de raios-x por dispersão de energia no equipamento MEV/EDS Tescan MIRA3. A caracterização microestrutural realizada nessa etapa empregou a nomenclatura proposta pelo International Institute of Welding (IIW) para a identificação das microestruturas observadas.

A partir das imagens de microscopia, estimou-se a proporção de cada fase nas zonas termicamente afetadas por análise estereológica, segundo método da contagem de pontos. Dessa forma, sobrepôs-se uma malha de 60 pontos às duas micrografias mais representativas de cada zona de interesse e considerou-se a fração pontual de cada fase equivalente à proporção da mesma. A fração pontual é definida pela razão entre o número de pontos incidentes em uma determinada fase e o número total de pontos da malha sobreposta à imagem micrográfica.

As juntas foram submetidas a inspeção via ultra-som para detecção de defeitos não-superficiais. 0 ensaio não-destrutivo foi realizado com aparelho EPOCH LTC, em serviço prestado pela Engequal Serviços Técnicos Ltda.

A fim de mapear os perfis de dureza ao longo das diferentes regiões do cordão de solda, foram realizados ensaios de microdureza Vickers sobre a superfície transversal ao cordão de solda de cada amostra. Os ensaios de microdureza foram executados em microdurômetro Emcotest Durascan G5, com aplicação de carga de 0,5 kg durante $15 \mathrm{~s}$ para cada impressão. 0 mapa de dureza foi elaborado com pontos intercalados a uma distância de 0,5 mm cada.

\section{Resultados e Discussão}

\subsection{Análise macrográfica}

As imagens macrográficas obtidas via estereoscópio, exibidas na Figura 5, permitiram a avaliação das características geométricas dos cordões de solda obtidos em cada condição estudada. Os valores aferidos para altura de reforço, penetração e largura de cada cordão estão dispostos na Tabela 5, na qual os passes vistos na posição inferior das macrografias são denominados 1 , correspondendo ao primeiro passe, e os vistos na posição superior, denominados 2 , correspondendo ao segundo passe. 


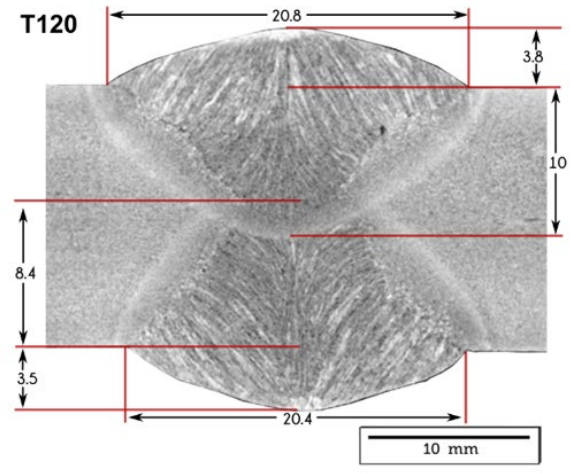

(a)

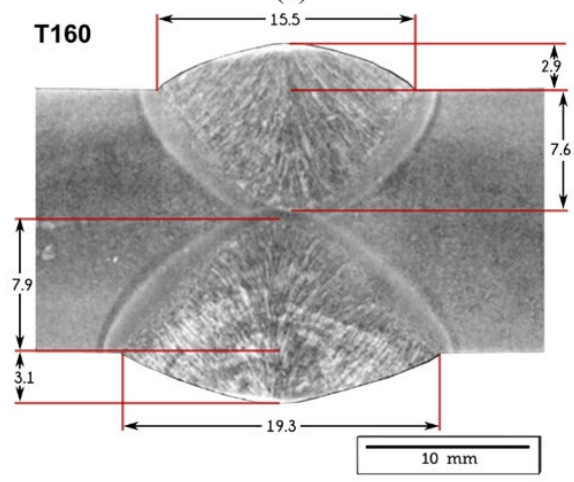

(c)

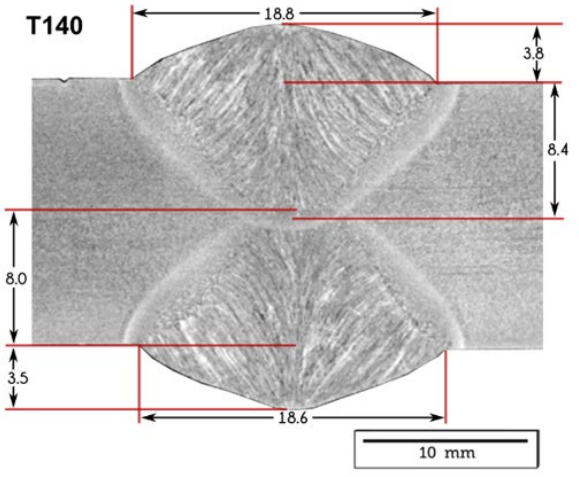

(b)

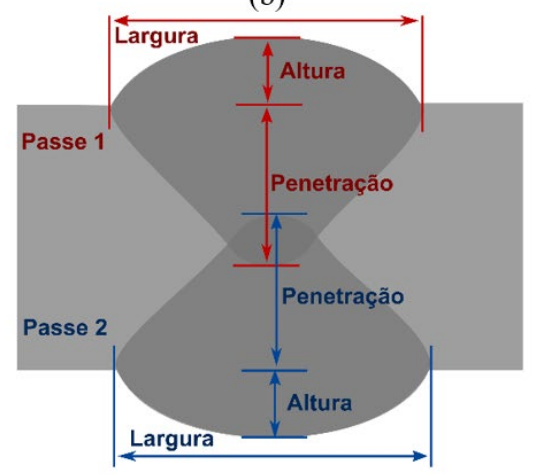

(d)

Figura 5. Macrografias transversais dos cordões das amostras: (a) T120; (b) T140; (c) T160; (d) esquema representativo das medidas da junta, todas as unidades em $\mathrm{mm}$.

A ausência de sobreposição entre os cordões da junta T160 indica que a mesma não apresentou penetração completa tampouco sobreposição entre os cordões de cada passe. Isto sugere que as condições de aporte térmico de T160 não proporcionaram fusão suficiente do material, de forma que seus cordões não tiveram penetração satisfatória e, consequentemente, não se sobrepuseram. Velocidades de soldagem mais elevadas, como é o caso da condição de soldagem da amostra T160, acarretam menor tempo para que ocorram os fenômenos de fusão e solidificação, visto que a exposição à energia de soldagem disponível torna-se mais breve. Por outro lado, a condição de maior aporte térmico, T120, apresentou em seu perfi macrográfico boa penetração e extensa sobreposição entre seus cordões de solda.

Tabela 5. Valores de parâmetros geométricos lineares medidos em perfil transversal ao cordão de solda.

\begin{tabular}{ccccc}
\hline Amostra & Passe & Largura $(\mathbf{m m})$ & Penetração $(\mathbf{m m})$ & Reforço $(\mathbf{m m})$ \\
T120 & 1 & $20,8 \pm 0,8$ & $10,0 \pm 0,3$ & $3,8 \pm 0,2$ \\
& 2 & $22,4 \pm 0,5$ & $8,4 \pm 0,2$ & $3,5 \pm 0,1$ \\
T140 & 1 & $18,8 \pm 0,7$ & $8,4 \pm 0,1$ & $3,8 \pm 0,3$ \\
& 2 & $18,6 \pm 0,5$ & $8,0 \pm 0,4$ & $3,5 \pm 0,2$ \\
T160 & 1 & $15,5 \pm 0,4$ & $7,6 \pm 0,2$ & $2,9 \pm 0,1$ \\
& 2 & $19,3 \pm 0,9$ & $7,9 \pm 0,3$ & $3,1 \pm 0,2$ \\
\hline
\end{tabular}

Apesar dos resultados obtidos por Sharma et al. [2] sugerirem suave diminuição de diluição com aumentos de aporte, os valores encontrados para esse parâmetro não apresentaram variação significativa entre os diferentes níveis de aporte térmico estudadas, assim como reportado por Shen et al. [16]. Para as três condições de soldagem analisadas, a diluição permaneceu próxima a 67,1\%, como representa graficamente a Figura 6 . A estabilidade desse parâmetro frente a variações significativas de aporte térmico - 17\% e 33\% - decorre da proporcionalidade entre as variações de área de reforço e de área de penetração. 


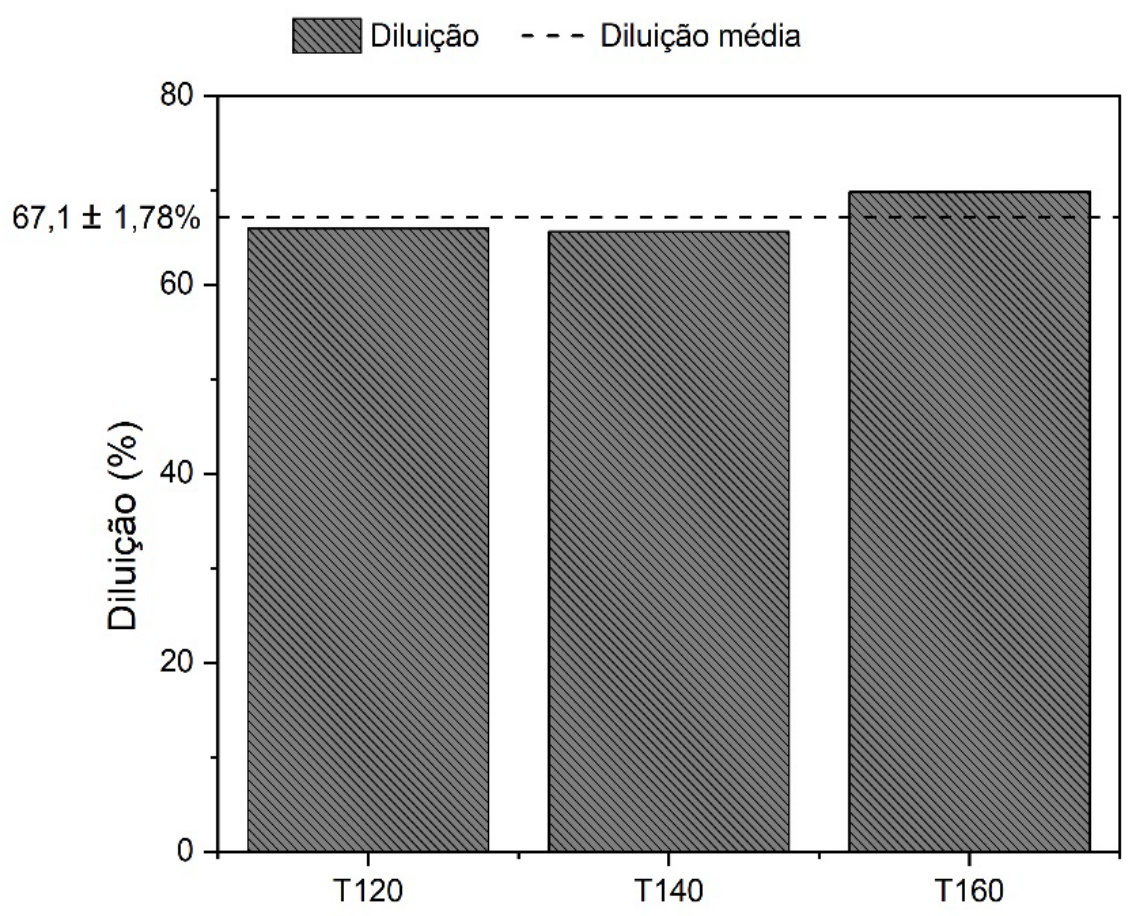

Figura 6. Valores encontrados para diluição em cada cordão de solda confeccionado.

Outro efeito constatado com as reduções de velocidade e decorrentes aumentos de calor fornecido foi a obtenção de valores maiores para o reforço e, em especial, a largura dos cordões, de modo que a região da solda passa a ocupar áreas maiores da seção transversal à medida que se avalia amostras de velocidade de soldagem cada vez menores. Como efeito potencialmente indesejado dessa tendência, destaca-se o aumento das zonas termicamente afetadas e o aumento de reforço.

A distribuição dos valores de parâmetros geométricos ao longo das amostras, exposta nos gráficos da Figura 6, ratifica 0 que se observou nos trabalhos de Shen et al. [16] e Sharma et al. [2], e demonstram que acréscimos de aporte térmico exercem efeito positivo sobre a formação do reforço, largura e penetração dos cordões de solda obtidos. Os resultados das medições das áreas de reforço e de penetração de cada cordão estão organizados na Tabela 6.

Tabela 6. Valores encontrados para área de penetração e área de reforço nos cordões.

\begin{tabular}{cccc}
\hline Amostra & Passe & Área de penetração $(\mathrm{mm})$ & Área do reforço $(\mathrm{mm})$ \\
T120 & 1 & 114,5 & 53,8 \\
& 2 & 92,6 & 52,4 \\
T140 & 1 & 85,2 & 44,6 \\
& 2 & 84,3 & 44,2 \\
T160 & 1 & 73,9 & 30,1 \\
\end{tabular}

Conforme apresentado na Figura 7, a altura do reforço sofreu leve aumento a partir das reduções de velocidade. Essa constatação ratifica o que afirmam os estudos de Gunaraj e Murugan [17], que indicam que esse parâmetro é majoritariamente governado pela tensão de soldagem, uma vez que neste trabalho apenas a velocidade de soldagem foi alterada. Em relação à largura de cordão, entretanto, o efeito negativo de incrementos de velocidade mostrou-se mais pronunciado em relação ao que se sugere em Gunaraj e Murugan [17].

Com o aumento do aporte térmico houve o incremento dos valores de área de penetração e reforço, conforme a Tabela 6 e os gráficos da Figura 8, indicando maior quantidade de metal de solda. Isso ocorre porque maiores velocidades de soldagem implicam em menor tempo para os processos de fusão e solidificação ocorrerem $[2,5,11]$, bem como menor volume de metal depositado por comprimento do cordão e menor aporte de calor introduzido. Por outro lado, a redução da velocidade de soldagem leva a maior quantidade de arame e metal de base fundidos, os quais permanecem em temperaturas acima à de fusão por mais tempo, provocando aumento da penetração, taxa de deposição, reforço e largura do cordão. 


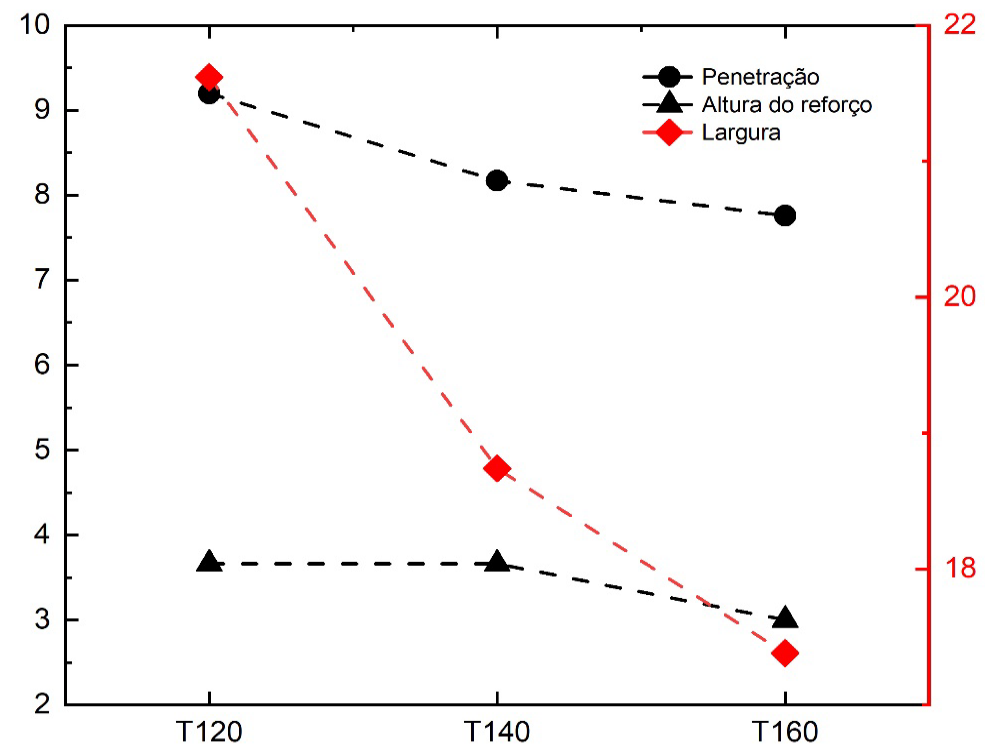

Figura 7. Distribuição dos valores de parâmetros geométricos lineares para as condições de soldagem estudadas.

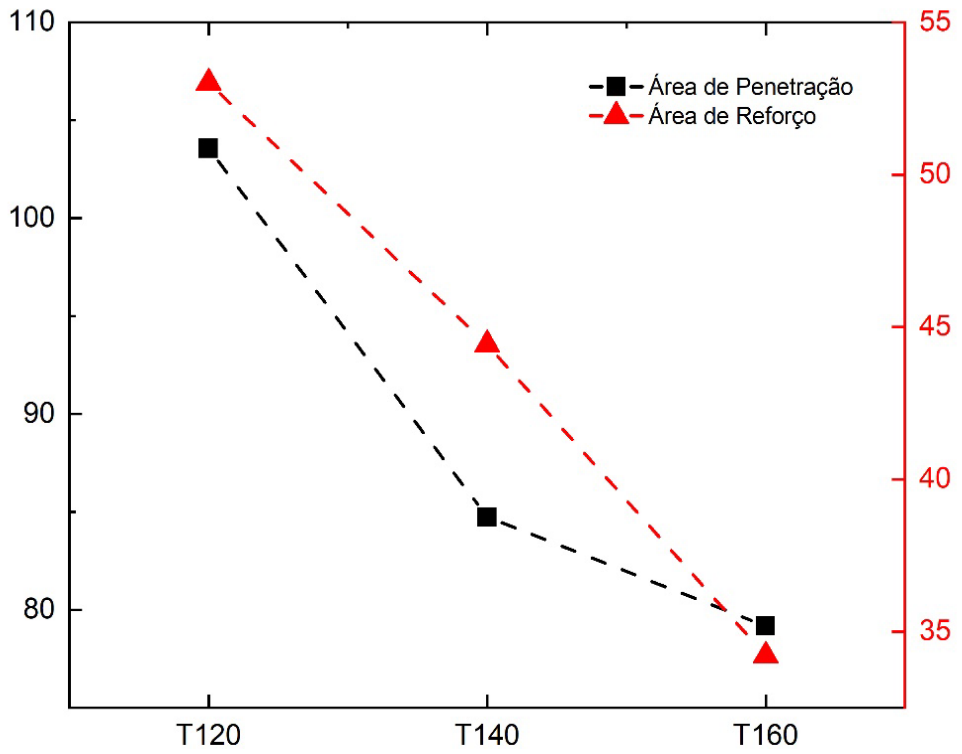

Figura 8. Distribuição das áreas de Penetração e de Reforço, medidas em seções transversais de cada cordão de solda.

\subsection{Ensaio de Ultrassom}

Através do ensaio de ultrassom, detectou-se em T140 a presença de vazios internos em trechos da junta. As condições de velocidade de soldagem dessa junta e a semelhança entre seu perfil transversal macrográfico e o de T160 sugerem que o defeito detectado nas duas é o mesmo: falta de penetração. Apesar disso, a extensão longitudinal do defeito ao longo das juntas difere entre T160 e T140, visto que em T140 há trechos em que os cordões se sobrepõem e, portanto, o defeito não está presente. A geometria de T140 representada nas macrografias corresponde aos trechos em que os cordões, de fato, estão sobrepostos, mas não é representativa da junta na totalidade de sua extensão. Para T120, por outro lado, o ensaio não detectou a presença de quaisquer descontinuidades ao longo de toda a junta.

Dessa forma, a única junta aprovada na inspeção de ultrassom foi a obtida na condição T120, em que as condições de soldagem garantiram que os cordões apresentassem penetração suficiente ao longo da soldagem de todo o comprimento da junta. Apesar da presença do defeito, as demais características morfológicas e a microestrutura observadas em T160 e T140 justificam que se mantenha o interesse nessas condições de soldagem, associadas a maiores taxas de produtividade e, portanto, reduções de custos. Uma vez que entender as características e resultados obtidos gerar conhecimento e dados para aprimorar o processo com uso de novas variáveis de soldagem. 


\subsection{Caracterização microestrutural}

\subsubsection{Microestrutura da ZTA}

Em termos de controle de processos de soldagem, as transformações metalúrgicas impostas à zona termicamente afetada despertam grande interesse acerca de sua microestrutura resultante. O material dessa zona sofre austenitização e é sujeito a taxas de resfriamento mais baixas que àquelas da zona fundida, o que tende a resultar em microestrutura mais grosseira. Como consequência desse fenômeno de alteração microestrutural, as propriedades mecânicas da ZTA, em especial a tenacidade à fratura desta, uma das regiões mais suscetível à falha por fratura em uma junta soldada $[13,16]$. O uso de aportes térmicos mais baixos encurta o tempo de permanência em temperaturas acima da austenitização e eleva as taxas de resfriamento, provocando menor crescimento de grão austenítico e inibindo a formação de microestrutura de grãos grosseiros [2,11].

A microestrutura das regiões de grãos grosseiros da ZTA (ZTAGG) de cada cordão soldado é representada na Figura 9. Observando as distinções microestruturais entre a condição de menor aporte térmico da Figura 9a, a condição intermediária da Figura 9b, e a condição de maior aporte térmico da Figura 9c, constata-se que elevações na quantidade de calor fornecido à junta soldada durante o processo resultam em grãos maiores, conforme apresentado na Tabela 7.

Apesar disso, as variações de taxa de resfriamento provocadas não acarretaram presença de microconstituintes diferentes em cada ZTA estudada. A ZTAGG dos três cordões identificou-se como principais microestruturas ferrita de Widmanstatten ( $\alpha$ W), ferrita com segunda fase alinhada (FSA), bainita (B) e ferrita primária de contorno de grão (PF(G)). Embora seja possível observar as quatro microestruturas na ZTAGG de todas as juntas soldadas, nota-se que a proporção de cada um na composição microestrutural da ZTA varia entre os três cordões de solda.

Notou-se que a morfologia da ferrita de Widmanstatten, originada nas ferritas de contorno de grão, variou de acordo com o nível de velocidade de soldagem. Observou-se que, na medida em que houve elevação de aporte térmico, as ripas de ferrita tornaram-se mais espessas. Outra diferença observada entre as microestruturas de ZTA é a diferença entre os tamanhos médio de grão, que apresentaram menor valor em T160, em decorrência do aporte térmico reduzido. Essa diferença, entretanto, é de baixa magnitude: de 5\% entre T120 e T140 e de 9\% entre T140 e T160.

As micrografias foram utilizadas para dimensionar o tamanho de grão médio na região de grãos grosseiros das ZTAs, utilizando o método de interceptos lineares, conforme definido pela norma ASTM E-112-12. O procedimento foi realizado com auxílio do software de acesso livre Goitacá. Os valores médios obtidos para tamanho de grão nas ZTAs encontram-se dispostos na Tabela 7.

Tabela 7. Tamanho médio de grão da ZTA dos cordões de solda.

\begin{tabular}{ccc}
\hline Amostra & Cordão & Tamanho de grão $(\mu \mathrm{m})$ \\
$\mathrm{T} 120$ & 1 & $154 \pm 14$ \\
$\mathrm{~T} 140$ & 1 & $147 \pm 17$ \\
$\mathrm{~T} 160$ & 1 & $134 \pm 19$ \\
\hline
\end{tabular}

A fim de verificar a presença de martensita na ZTA de T160, realizou-se ataque químico com reagente de Le Pera. Devido à ação do reagente na superfície da amostra, estruturas martensíticas e austeníticas são observadas em tonalidades de branco em microscopia óptica. Em contraste, ferritas aparecem em tons de azul a verde e bainitas na cor marrom. A condição T160 foi selecionada para essa análise por apresentar as maiores taxas de resfriamento e, portanto, a maior probabilidade de conter martensita ou martensita revenida. A suspeita se deu, pois, taxas de resfriamento elevadas podem levar o material a temperaturas abaixo daquela em que se forma martensita, antes que as transformações de formação de ferrita acicular e bainita possam ser concluídas. As imagens obtidas estão expostas na Figura 10.

Como visto na Figura 10, a análise microestrutural não apontou a presença de quaisquer microconstituintes martensíticos, de modo que as maiores taxas de resfriamento influenciaram a microestrutura resultante de maneira exclusivamente positiva. Percebe-se na Figura 10a que as porções azuis passam a ocupar mais espaço na imagem à medida em que se distancia do centro do cordão. Isso pode ser justificado pelo fato de que as taxas de resfriamento diminuem com a distância ao centro, favorecendo formação de morfologias de ferrita em detrimento das bainíticas.

A bainita, identificada na análise de microscopia óptica, esteve distribuída ao longo das ZTAGGs na forma de ilhas, contidas no interior dos grãos. Através da análise via microscopia eletrônica de varredura, a morfologia de bainita pôde ser vista em mais detalhes, como mostra a Figura 11. Destaca-se o alto grau de refino da estrutura, composta de feixes de carbetos alongados de dimensões nanométricas e altamente dispersos na matriz ferrítica, conforme indicado na imagem de microscopia contida na Figura 11 e os respectivos aumentos em imagens de MEV [19-21]. 


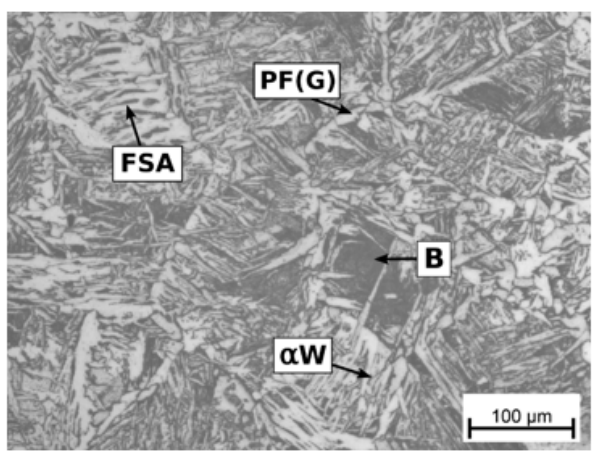

(a) $\mathrm{T} 120$

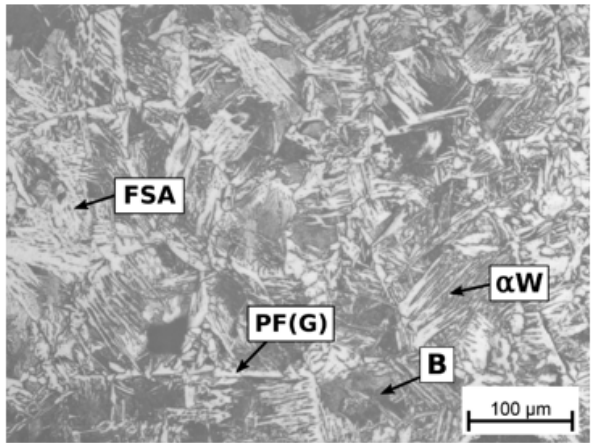

(b) $\mathrm{T} 140$

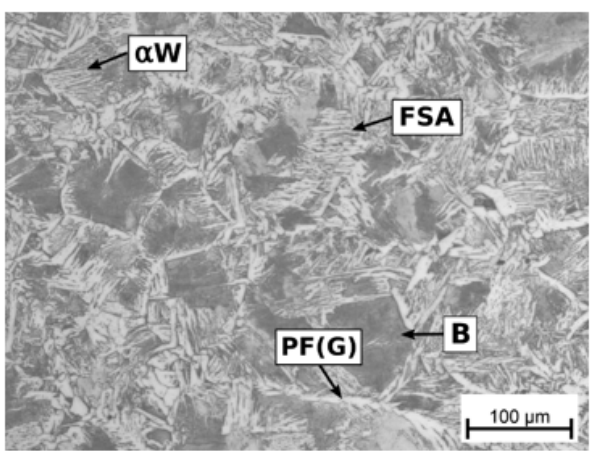

(c) $\mathrm{T} 160$

Figura 9. Micrografias da Região de Grãos Grosseiros nas ZTAs (a) T120; (b) T140 e (c) T160.

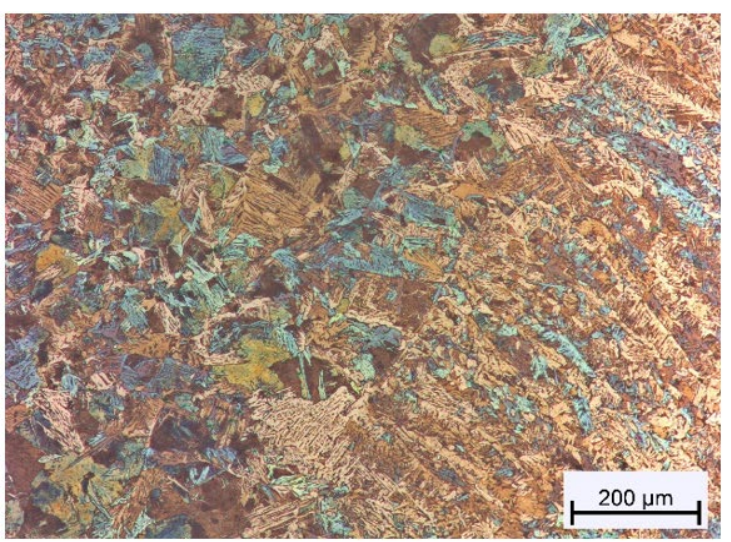

(a)

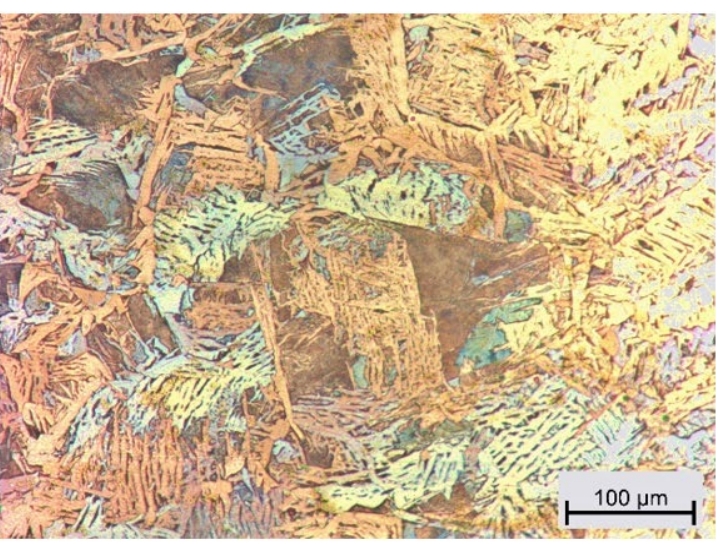

(b)

Figura 10. Micrografias de T160, após ataque com reagente Le Pera. $\mathrm{O}$ ataque realça a distinção entre os constituintes ferríticos e bainíticos. A interface entre ZF e ZTA é vista em (a). 


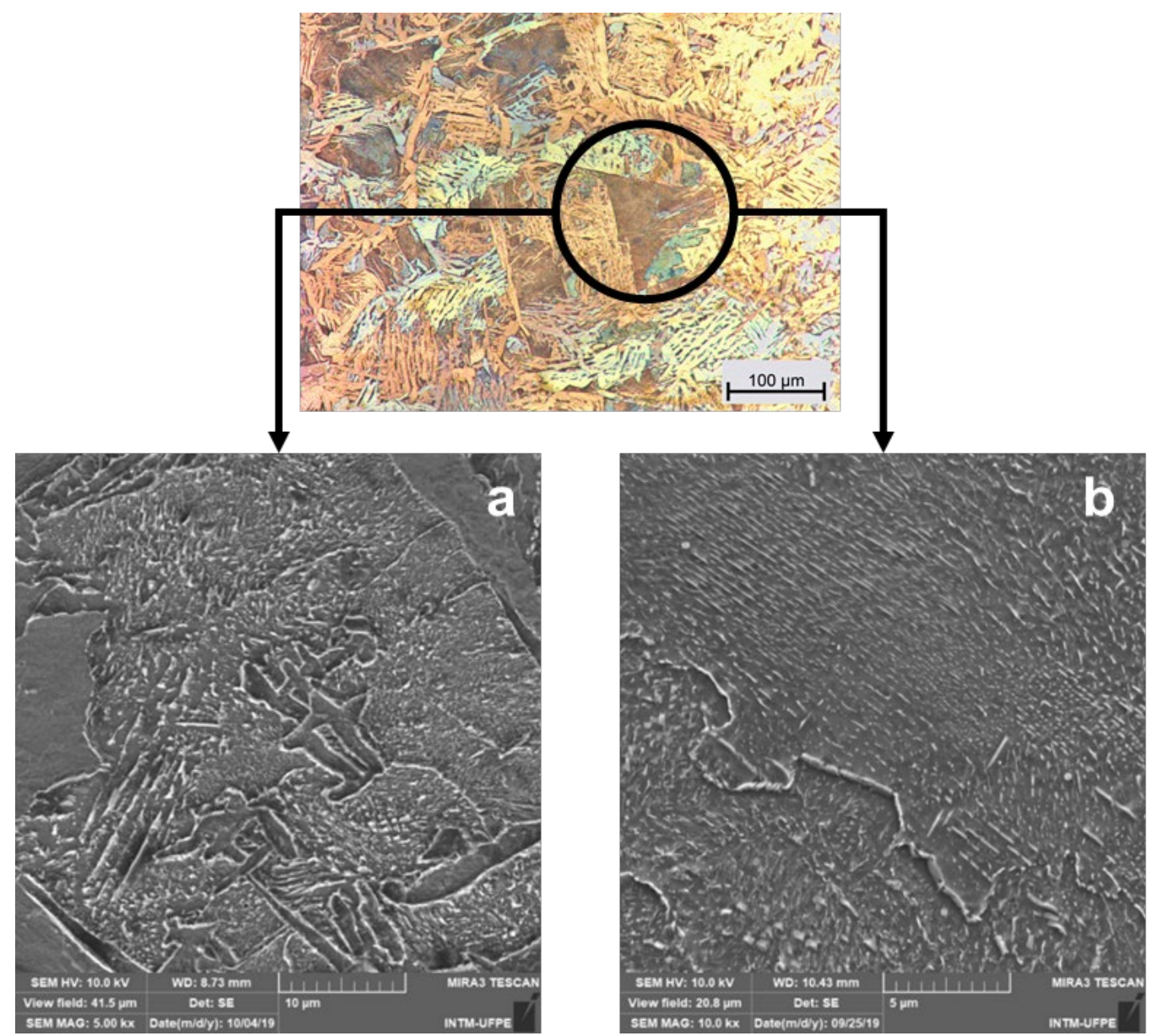

Figura 11. Imagem de Microscopia eletrônica de varredura evidenciando a presença de bainita na ZTA. (a) Aumento de 5 mil vezes. (b) Aumento de 10 mil vezes.

Conforme reportado em Sirin et al. [22] e Lan et al [23], aportes térmicos elevados provocam maior crescimento de grão, pois acréscimos na entrada de calor reduzem as taxas de resfriamento de maneira potencialmente excessiva, comprometendo a resistência mecânica da junta por aumentarem as dimensões da ZTA e da região de grãos grosseiros.

\subsubsection{Microestrutura da ZF}

A microestrutura presente na zona fundida das juntas obtidas é composta majoritariamente de morfologias de ferrita, em especial a ferrita acicular (AF), ferrita primária de contorno de grão (PF(G)) e ferrita com segunda fase alinhada (FSA). As micrografias de menor magnificação apresentam o perfil colunar de crescimento característico de ZFs de aços carbono e aços baixa liga $[1,18,23]$. As microestruturas características da ZF de cada cordão estão dispostas na Figura 12.

A bainita (B) e a ferrita acicular (AF) se formam por mecanismos de transformação similares, diferindo principalmente em seus sítios de nucleação. A ferrita acicular (AF) nucleia em inclusões presentes no interior de grãos austeníticos, enquanto a bainita nucleia em contornos entre grãos austeníticos ou entre grão ferrítico e grão austenítico [14,17,18,20]. Durante a solidificação enquanto houver contornos disponíveis, a bainita é favorecida cineticamente em relação à AF. Entretanto, uma vez que se tenha formado a ferrita alotriomórfica ao longo dos contornos de grão, a cinética de formação da ferrita acicular se favorece [19-21,24].

A predominância de AF nos interiores de grão e a presença extensiva de ferrita primária de contorno de grão ao longo da ZF indica que, durante o resfriamento, formou-se camada de PF(G) ao longo dos contornos de grão antes que se atingisse a temperatura de nucleação de B ou AF. Com isso, a formação de AF nas inclusões intragranulares tomou preferência frente à nucleação de bainita. A formação de inclusões devido à dissolução de elementos mais leves nas temperaturas mais altas do processo de soldagem é outro fator de favorecimento da transformação em ferrita acicular, conforme fenômeno discutido por Babu $[19,25]$.

Em T120, após a ocupação dos contornos pela $P F(G)$, as taxas de resfriamento inferiores permitiram a nucleação e crescimento da ferrita de Widmanstatten $(\alpha \mathrm{W})$, vista em Figura 11f, a partir da mesma. Em T140 e T160, por outro lado, essa estrutura teve menos tempo para se desenvolver, visto que a temperatura a partir do qual a formação de AF prevalece foi atingida mais rapidamente. 

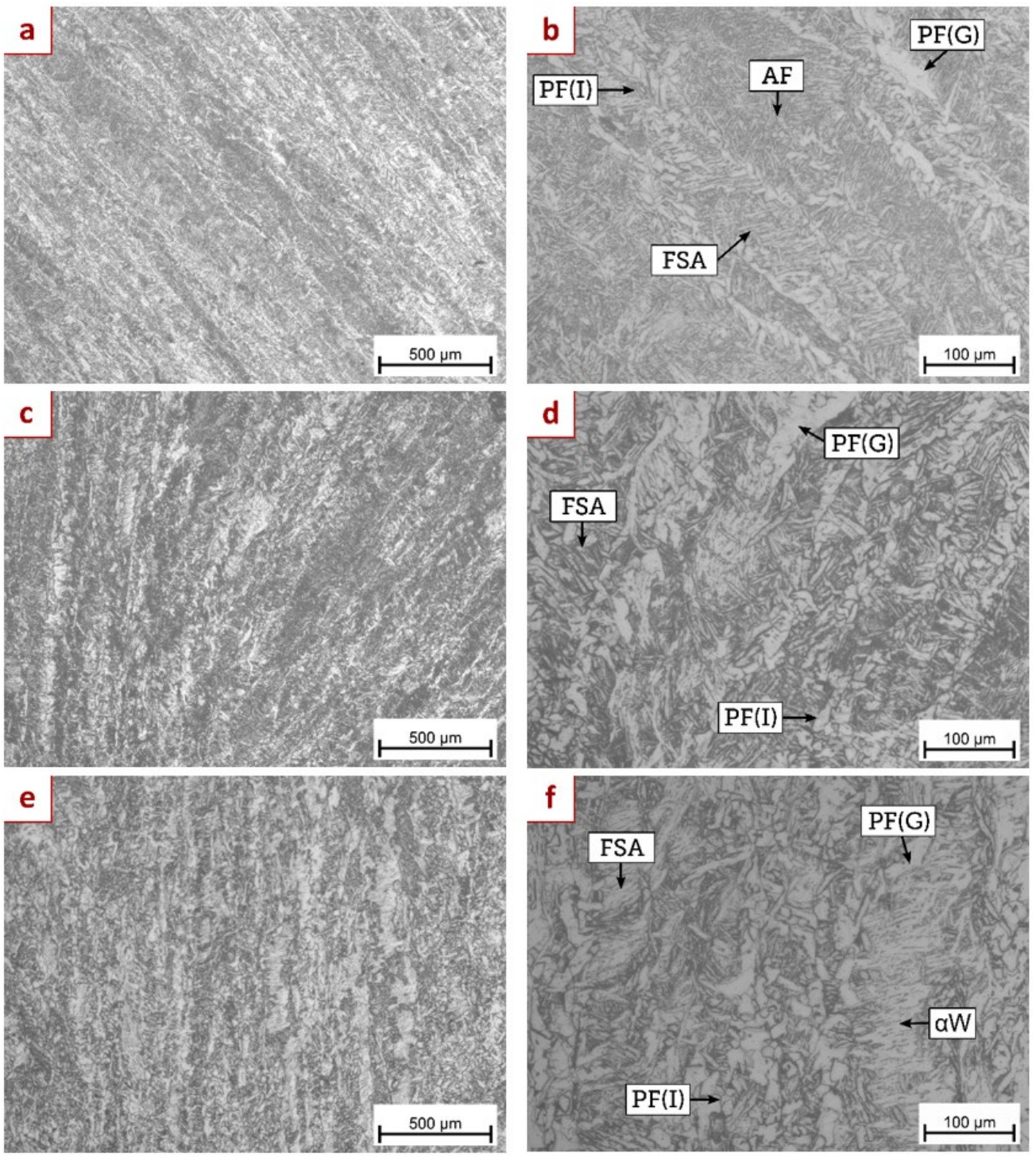

Figura 12. Imagens de microscopia óptica - com aumentos de 50 vezes em a, c, e e 200 vezes em b, d, f - das microestruturas de T160 (a, b), $\mathrm{T} 140$ (c, d) e T120 (e, f).

Morfologicamente, a ferrita acicular apresenta, em cada ripa unitária, maior comprimento com relação a seção transversal em uma de suas direções, dando o formato de agulhas. Suas unidades morfológicas aparecem com orientação aleatória, em conjuntos entrelaçados caoticamente. Essa morfologia característica é resultado de repetidas transformações por cisalhamento na estrutura cristalina da fase originária, que leva ao rápido crescimento adifusional de microconstituintes AF previamente nucleados, de maneira análoga ao mecanismo cinético observado em bainitas, diferindo deste por suas múltiplas direções de crescimento radial desordenado $[15,16,19,25]$.

Comparando as micrografias de cada junta, nota-se que com o acréscimo de velocidade há aumento na quantidade de ferrita acicular, conforme Tabela 8. Dado o efeito positivo que essa microestrutura exerce nas propriedades mecânicas do material, em especial na tenacidade e resistência mecânica, a tendência observada mostra a viabilidade para o emprego de velocidades mais elevadas durante a soldagem de SAW-T. Esse fenômeno ocorre porque velocidade de resfriamento maior atrelados ao aumento da velocidade e, consequente, diminuição de aporte térmico, propiciam a formação de microestruturas aciculares, como a ferrita acicular $[1,7,11,25]$.

Tabela 8. Porcentagem de Ferrita Acicular (AF) nos cordões de solda.

\begin{tabular}{ccc}
\hline Amostra & Cordão & \% AF \\
T120 & 1 & $28,1 \%$ \\
T140 & 1 & $51,6 \%$ \\
T160 & 1 & $57,9 \%$ \\
\hline
\end{tabular}


Reduções de velocidade de soldagem, por outro lado, promovem maior formação de ferrita de contorno de grão, microestrutura considerada indesejável. Além disso, permanências mais duradouras em temperatura elevadas e resfriamentos mais lentos, ambos observados em aportes térmicos mais elevados, propiciam o crescimento de grão e reduzem a taxa de nucleação $[13,25,26]$. O aporte térmico é o principal fator de influência no tamanho de grão austenítico prévio e na largura das ripas de ferrita acicular [9]. Esses dois parâmetros são negativamente influenciados por diminuições na taxa de resfriamento decorrentes de aportes térmicos maiores, que tornam a microestrutura mais grosseira de forma geral.

\subsection{Mapeamento de Dureza}

Os mapas de dureza obtidos para as amostras T160 e T120 são apresentados pela Figura 13. Por se tratar do par com maior discrepância de aporte térmico entre si, a comparação entre as distribuições de dureza deles é a que mais contribui à compreensão do efeito de variações de aporte térmico nos componentes microestruturais obtidos com o ciclo térmico do processo de soldagem.
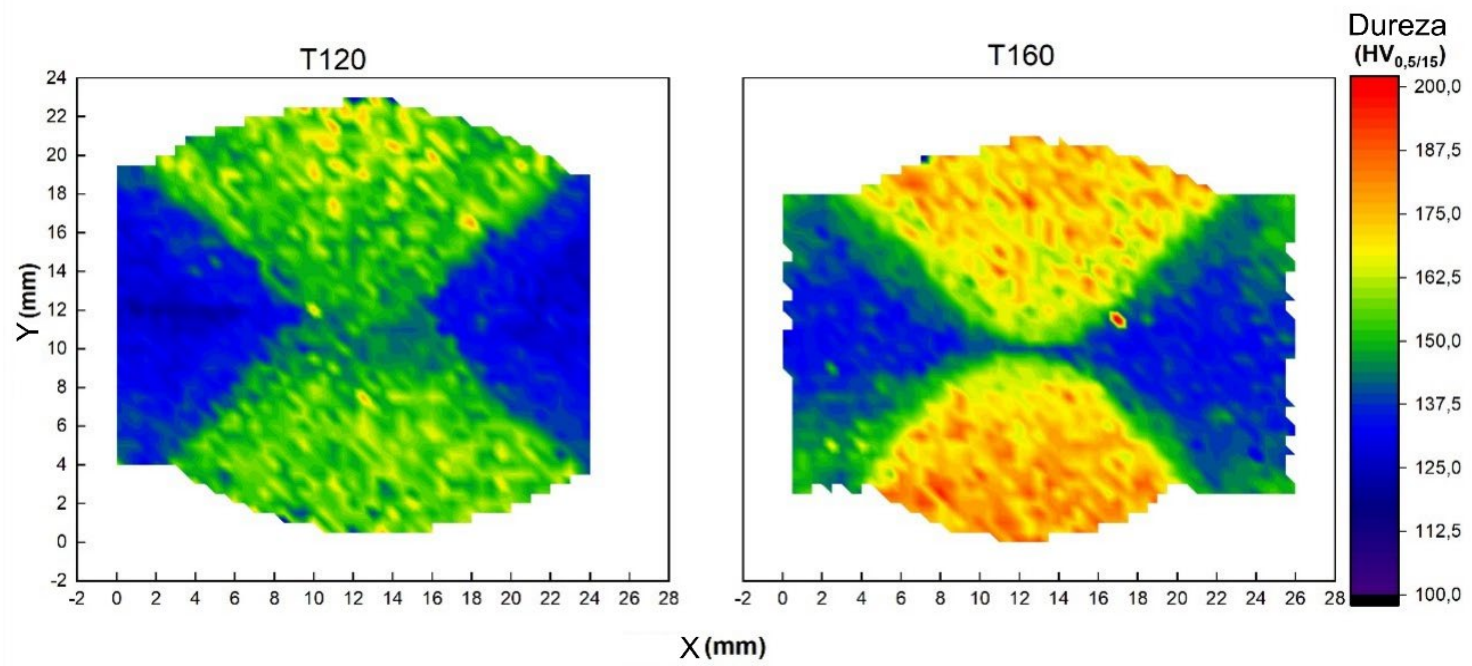

Figura 13. Mapas de dureza dos cordões soldados nas condições T120 e T160.

A Figura 14 apresenta a média da dureza na ZTA e zona fundida das amostras T120 e T160. Através da distinção entre a dureza apresentada em cada condição estudada constata-se que reduções de aporte térmico levam a durezas mais elevadas no material modificado pelos ciclos térmicos do processo. Isso se deve, principalmente, às propriedades mecânicas demonstradas por microestruturas formadas sob maiores taxas de resfriamento, conforme reportado em Barbosa et al. [26].

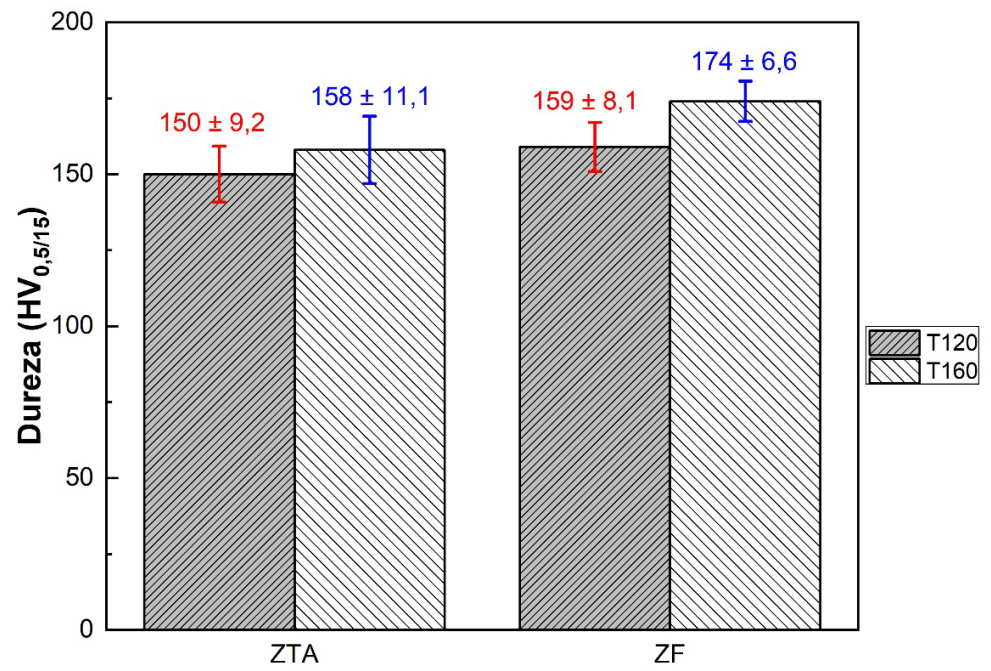

Figura 14. Média da dureza na ZTA e ZF das condições T120 e T160. 
A elevação de valores de dureza identificada nas regiões da junta se dá principalmente pela formação de microestruturas de morfologia altamente refinada como ferrita acicular, que conferem ao material melhor comportamento mecânico, por oferecerem maior oposição à propagação de trincas e possuírem resistência mecânica mais elevada $[4,13,18,20]$. Os resultados correspondem ao que se espera a partir da distribuição de microconstituintes observada na análise microestrutural. A introdução de tensões residuais provenientes do ciclo térmico no material pode ter contribuído com o aumento da dureza.

Os valores mais altos de T160 decorrem do fato de que esse cordão apresentou, em sua ZTA, a maior proporção de bainita. É em sua ZF que se encontra AF em maior quantidade, com morfologias mais finas e numerosas. Os efeitos dessa microestrutura puderam ser observados nos resultados de microdureza, visto que a influência positiva dos microconstituintes citados nas propriedades mecânicas da junta incluem a dureza.

Nota-se que a distribuição de valores de dureza ao longo dos cordões de T120 é mais homogênea, com menor diferença entre valores mínimo e máximo em seu metal de solda. Isso indica menor variabilidade de microestrutura ao longo da região, o que reflete a consistência observada na caracterização microestrutural. O efeito de aumento de dureza nessa amostra é menos pronunciado, na qual o aumento de propriedades mecânicas foi limitado pela presença de maior quantidade de ferrita de contorno de grão e ferrita com segunda fase alinhada, que cresce a partir do contorno de grão [8,12,27]. Além disso, as taxas de resfriamento menores nessa amostra resultaram a estrutura de grãos, de forma geral, menos refinada $[7,11]$.

\section{Conclusões}

- $\quad$ Foram produzidas, por soldagem a arco submerso tandem arc, três juntas de topo entre chapas de $16 \mathrm{~mm}$ sem chanfro do aço ASTM A572 GR.50. A velocidade de soldagem de 1200 mm/min resultou, nas condições de potência estudadas, em junta de geometria robusta, com sobreposição entre cordões opostos.

- As juntas soldadas a $1600 \mathrm{~mm} / \mathrm{min}$ e $1400 \mathrm{~mm} / \mathrm{min}$ apresentaram defeito de falta de penetração, indicando que o aporte térmico nessas condições de soldagem é inadequado por não promover fusão suficiente de material, levando à baixa penetração e impedindo a sobreposição dos cordões. Em T160, esse fenômeno foi observado ao longo de toda a junta, enquanto T140 apresentou trechos em que isso não se mostrou um problema.

- A microestrutura das juntas, consistindo predominantemente de diferentes morfologias de ferrita, recebeu influência positiva de aumentos de velocidade de soldagem. Essa influência foi constatada através da redução dos tamanhos de grão, e aumento do teor de microconstituintes de maior resistência mecânica, como ferrita acicular nas ZFs e bainita nas ZTAs. $O$ efeito em questão deve-se ao fato de que velocidades de soldagem mais elevadas implicam em menor tempo para crescimento de grão e taxas de resfriamento mais altas.

- Dentre as condições estudadas, destaca-se especialmente T120, em que os parâmetros empregados levaram à formação de juntas com microestrutura de boas propriedades mecânicas e junta de geometria robusta, havendo sobreposição entre os cordões. Esse valor de velocidade é consideravelmente superior aos usuais em processos SAW-T sem chanfro, de forma que a implementação dessa condição de soldagem representa potenciais ganhos em produtividade na fabricação de juntas de bom desempenho mecânico.

- A fim de viabilizar velocidades como as utilizadas em T140 e T160, são necessárias otimizações ou adaptações adicionais do processo. Medidas com potencial de aumentar a penetração dos cordões e evitar o defeito encontrado incluem aumentos de corrente de soldagem, uso de chanfro, pré-aquecimento das chapas e diminuição da angulação do arame guiado. Apesar de terem diminuído a penetração, o que eventualmente propiciou a formação do defeito, esses incrementos de velocidade estão associados a ganhos em taxas de produtividades e a juntas de qualidade consideravelmente superior em termos de microestrutura, o que justificaria esse esforço de otimização.

\section{Agradecimentos}

Os autores agradecem à FACEPE, CAPES, CNPq e MEMPS Tubos Helicoidais por apoio financeiro (bolsa e auxílio financeiro); ao INTM (FINEP, ANP/Petrobras) e ESAB Brasil pelo uso da infraestrutura e pelo fornecimento dos insumos para realização do estudo.

\section{Referências Bibliográficas}

[1] Silva ACS, Figueredo EWA, Silva Júnior DC, Hermenegildo TFC, Santos TFA. Soldagem helicoidal de tubos produzida em campo do aço ASTM A-1018 e sua correlação com características mecânicas e microestruturais das juntas soldadas. Soldagem e Inspeção. 2018;23(3):364-379. http://dx.doi.org/10.1590/0104-9224/si2303.06.

[2] Sharma SK, Maheshwari S, Singh RKR. Effect of heat-input and cooling-time on bead characteristics in SAW. Materials and Manufacturing Processes. 2019;34(2):208-215. http://dx.doi.org/10.1080/10426914.2018.1532578. 
[3] Ferrari M, Das Neves MDM, Panão JN. Análise das propriedades mecânicas de juntas de aço carbono estrutural soldadas pelo processo arco submerso com os arcos simples e duplo (Tandem-Arc). Soldagem e Inspeção. 2019;24:e2402. http://dx.doi.org/10.1590/01049224/si2304.07.

[4] Ribeiro ACN. Avaliação da soldagem do aço naval AH36 microligado soldado pelo processo arco submerso com um e dois arames [dissertação de mestrado]. Escola Politécnica da Universidade de São Paulo, São Paulo; 2015.

[5] Singh RP, Garg RK, Shukla DK. Parametric effect on mechanical properties in submerged arc welding process - A review. International Journal of Engineering Science and Technology. 2012;4:747-757.

[6] Kiran DV, Na S-J. Experimental studies on submerged arc welding process. Journal of Welding and Joining. 2014;32(3):1-10. http://dx.doi.org/10.5781/JWJ.2014.32.3.1.

[7] Kiran DV, Cho D-W, Lee H-K, Kang CY, Na S-J. A study on the quality of two-wire tandem submerged arc welds under iso-heat input conditions. International Journal of Advanced Manufacturing Technology. 2015;78(1-4):53-62. http://dx.doi.org/10.1007/s00170-0146644-3.

[8] Kolhe KP, Datta CK. Prediction of microstructure and mechanical properties of multipass SAW. Journal of Materials Processing Technology. 2008;197(1-3):241-249. http://dx.doi.org/10.1016/j.jmatprotec.2007.06.066.

[9] Viano DM, Ahmed NU, Schumann GO. Influence of heat input and travel speed on microstructure and mechanical properties of double tandem submerged arc high strength low alloy steel weldments. Science and Technology of Welding and Joining. 2000;5(1):26-34. http://dx.doi.org/10.1179/stw.2000.5.1.26.

[10] Ghosh A, Chattopadhyaya S, Sarkar PK. Effects of input parameters on weld bead geometry of saw process. In: International Association of Engineers. Proceeding of the International Conference on Mechanical Engineering: ICME 2007; 2007 December 29-31; Dhaka, Bangladesh. Hong Kong, China: ICME; 2007.

[11] Farhat $\mathrm{H}$. Effects of multiple wires and welding speed on the microstructure and properties of submerged Arc Welded X80 Steel [master's thesis]. Saskatoon, SK: University of Saskatchewan; 2007.

[12] Barbosa LHS, Modenesi PJ, Godefroid LB, Borba TMD. Microestrutura e características mecânicas da zona fundida de um aço naval soldado ao arco submerso com aporte térmico muito elevado. Soldagem e Inspeção. 2018;23(2):168-179. http://dx.doi.org/10.1590/0104-9224/si2302.05.

[13] Thewlis G. Classification and quantification of microstructures in steels. Materials Science and Technology. 2004;20(2):143-160. http://dx.doi.org/10.1179/026708304225010325.

[14] Abson DJ. Acicular ferrite and bainite in C-Mn and low-alloy steel arc weld metals. Science and Technology of Welding and Joining. 2018;23(8):635-648. http://dx.doi.org/10.1080/13621718.2018.1461992.

[15] Loder D, Michelic S, Bernhard C. Acicular ferrite formation and its influencing factors - A review. Journal of Materials Science Research. 2016;6(1):p24. http://dx.doi.org/10.5539/jmsr.v6n1p24.

[16] Shen S, Oguocha INA, Yannacopoulos S. Effect of heat input on weld bead geometry of submerged arc welded ASTM A709 Grade 50 steel joints. Journal of Materials Processing Technology. 2012;212(1):286-294. http://dx.doi.org/10.1016/j.jmatprotec.2011.09.013.

[17] Gunaraj V, Murugan N. Prediction of heat-affected zone characteristics in submerged arc welding of structural steel pipes. Welding Research. 2008;81:94-98.

[18] Lippold JC. Welding metallurgy and weldability. Hoboken, NJ: John Wiley \& Sons Inc; 2015. http://dx.doi.org/10.1002/9781118960332

[19] Santos TF, Torres EA, Vilela JM, Andrade MS, Cota AB. Caracterização microestrutural de aços baixo carbono por microscopia de força atômica. Revista Latinoamericana de Metalurgia y Materiales. 2014;35(1):118-133.

[20] Krauss G. Steels: processing, structure, and performance. 2nd ed. Materials Park, OH: ASM International; 2015. http://dx.doi.org/10.31399/asm.tb.spsp2.9781627082655.

[21] EILISES, C.; HASHIMOTO, T.; ABDALLA, A.; PEREIRA, M. Caracterização mecânica e microestrutural de um aço baixo carbono microligado com estrutura multifásica Mechanical and microstructural characterization of a multiphase microalloyed steel. Revista Matéria, 2008;13(2):398-404.

[22] Sirin K, Sirin SY, Kaluc E. Influence of the chemical composition of weld electrode on the mechanical properties of submerged arc welded pipe. International Journal of Advanced Manufacturing Technology. 2016;87(5-8):1941-1950. http://dx.doi.org/10.1007/s00170-0168546-z.

[23] Lan LY, Qiu CL, Zhao DW, Gao XH, Du LX. Effect of single pass welding heat input on microstructure and hardness of submerged arc welded high strength low carbon bainitic steel. Science and Technology of Welding and Joining. 2012;17(7):564-570. http://dx.doi.org/10.1179/1362171812Y.0000000048.

[24] Babu SS, David SA. Inclusion formation and microstructure evolution in low alloy steel welds. ISIJ International. 2002;42(12):1344-1353. http://dx.doi.org/10.2355/isijinternational.42.1344. 
[25] Babu SS. The mechanism of acicular ferrite in weld deposits. Current Opinion in Solid State and Materials Science. 2004;8(3-4):267-278. http://dx.doi.org/10.1016/j.cossms.2004.10.001.

[26] Barbosa LHS. Propagação de trincas por fadiga na zona fundida de soldas obtidas em único passe com altíssima energia de soldagem através do processo SAW com adição de arame frio em um Aço EH36 [tese de doutorado]. Universidade Federal de Minas Gerais; 2018.

[27] Ribeiro ACN, Henein H, Ivey DG, Brandi SD. Evaluation of AH36 microalloyed steel welded joint by submerged arc welding process with one and two wires. Materials Research. 2016;19(1):143-152. http://dx.doi.org/10.1590/1980-5373-MR-2015-0532. 